\title{
6
}

\section{VARIAÇÃO PRAGMÁTICA DE ATOS DE FALA DIRETIVOS DO ESPANHOL NA TRÍPLICE FRONTEIRA: ARGENTINA, BRASIL E PARAGUAI}

\section{PRAGMATIC VARIATION OF SPANISH DIRECTIVE SPEECH ACTS IN THE TRIPLE BORDER: ARGENTINA, BRAZIL AND PARAGUAY \\ Natalia dos Santos Figueiredo 1 Universidade Federal da Integração Latino-americana}

Resumo: Neste trabalho apresentamos a descrição do ato de fala diretivo pedido em 4 variedades do espanhol: Assunção e Buenos Aires; e 2 cidades fronteiriças: Ciudad del Este, no Paraguai, e Puerto Iguazú, na Argentina. Contrastamos as estratégias de cortesia utilizadas por locutores dessas 4 localidades, em interações com estímulos contextualmente controlados, através da descrição da variação pragmática. Os resultados revelam convergências entre as variedades de fronteira, indicando a existência de um dialeto próprio regional, e padrões mais divergentes na variedade de Buenos Aires, que podem resultar em mal-entendidos pragmáticos na interação entre os falantes de diferentes localidades.

Palavras-Chave: Variação Pragmática; Ecologia das línguas; Línguas em Contato.

1 Endereço eletrônico: natalia.figueiredo@unila.edu.br. 


\begin{abstract}
In this paper we present a description of requests, a directive speech act in 4 varieties of Spanish: Asunción and Buenos Aires; and 2 border cities, Ciudad del Este, in Paraguay, and Puerto Iguazú, in Argentina. We contrasted the courtesy strategies used by speakers from these 4 locations, in interactions with contextually controlled stimuli, through the description of pragmatic variation. The results reveal convergences between the border varieties, indicating the existence of a specific regional dialect, and more divergent patterns in the Buenos Aires variety, which can result in pragmatic misunderstandings in the interaction between speakers from different locations.
\end{abstract}

Keywords: Pragmatic Variation; Ecology of languages; Languages in contact.

\title{
INTRODUÇÃO
}

Ao estudarmos a variação pragmática do espanhol, podemos encontrar referências sobre a análise de algumas variedades da língua. Em nosso objeto desta pesquisa, trabalhamos com a variedade de Buenos Aires, que possui uma produção relevante de pesquisas referentes a sua descrição linguística; e as variedades de Assunção, Ciudad del Este e Puerto Iguazú, que carecem de dados descritivos de referência. Outras regiões argentinas como a do Chaco, e as províncias de Misiones e Corrientes, que são terras originariamente guaraníticas e com fronteiras transnacionais e territórios compartilhados entre o Brasil, o Paraguai e a Argentina, estão muito pouco ou nada descritas, sobre tudo no que se refere à variação pragmática.

Desta forma, realizamos a descrição da variação pragmática do ato de fala pedido considerando a ecologia das línguas em uma região de contato linguístico-cultural. Nos perguntamos qual a identidade de fronteira que prevalece no contato entre as populações de Ciudad del Este (Paraguai) e Puerto Iguazú (Argentina) em relação às suas respectivas capitais e centros de poder, Assunção (Paraguai) e Buenos Aires (Argentina). Temos, portanto, como objetivo deste trabalho contrastar as estratégias pragmáticas utilizadas pelos falantes das 4 cidades pesquisadas, observando traços de convergência e divergência que nos permitam pensar a relação de contato e coesão regional (práticas cotidianas, 
trocas comerciais e familiares) frente a centros de poder (influência midiática, zona de prestígio, restrições econômicas).

As análises dos dados foram realizadas em dois níveis, que levam em consideração as estratégias de cortesia adotadas pelos falantes das quatro cidades para produzir enunciados representando o ato de fala diretivo pedido: a análise pragmática das estratégias de atenuação e intensificação do ato de fala e o grau de direticidade ou indireticidade (indirectness) ${ }^{2}$ na formulação do mesmo. Levantamos como hipótese que esse grau não é o mesmo nas diferentes localidades, e acreditamos que Buenos Aires seja divergente em termos de tentativas e indireticidade. Nos baseamos nos estudos de Márquez-Reiter (2002), que destaca resultados de pesquisas que demonstram mal-entendidos pragmáticos entre falantes de diferentes variedades do espanhol e relatos informais de falantes de outras variedades do espanhol quanto à percepção da fala porteña como mais direta na produção de atos de fala diretivos.

Finalmente, relacionamos os resultados obtidos nas diferentes análises para confirmar ou não as relações de contato entre as variedades de fronteira e descrever padrões linguísticos e pragmáticos ainda não conhecidos dessas 4 variedades do espanhol, e que mantêm relações entre si. Pretendemos com esta pesquisa fornecer subsídios na forma de dados de variação pragmática para a caracterização do espanhol nesta região de fronteira ainda pouco descrita. Esta descrição nos permitirá estabelecer discussões sobre variedades dominantes e não dominantes do espanhol com relação aos centros econômicos de poder e às representações linguísticas promovidas por eles.

2 Optamos pelo uso da tradução dos termos directness e indirectness, conforme utilizado em inglês por Márquez-Reiter (2002), para manter a aproximação com a referência citada. Esses termos também foram adotados em Figueiredo (2018). 
Os atos de fala, ou Speech Acts em inglês, se configuram com elemento central da teoria de Searle (1969), que retoma a hipótese de Austin (1962) como base, considerando que todo o enunciado linguístico funciona como um ato particular, e implica alguma alteração na interação. Para Searle (1969), falar uma língua é apropriar-se de uma forma de conduta organizada por regras, e no caso de uma língua que possui diversas variedades e está em contato com outras tantas línguas, como é o caso do espanhol, essas regras tendem a multiplicar-se, gerando formas e resultados distintos. Neste caso, torna-se importante e necessária a descrição dessas variedades para evitar a predominância de teorias etnocêntricas, restritas à análise apenas de variedades dominantes (PLACENCIA \& BRAVO, 2002).

Ainda segundo Searle (1969, p.13), o ato de fala diretivo é aquele no qual o falante espera que o ouvinte realize uma ação, sendo considerado o ato de fala mais ameaçador e, portanto, o mais propício para o estudo das diferenças sociais e culturais da valoração pragmática (FÉLIX-BRASDEFER, 2011). A partir dessa teoria, alguns estudos contrastivos sobre os atos de fala em diferentes línguas e culturas foram realizados, porém ainda são escassos os trabalhos sobre o espanhol e suas variedades.

Para este trabalho, consideramos a variedade de Buenos Aires como dominante do espanhol em sua região, enquanto Assunção, Ciudad del Este e Puerto Iguazú formam parte das variedades não-dominantes da língua.

\section{1 (In)direticidades de variedades do espanhol}

Segundo Márquez-Reiter (2002, p. 135-136), muitos estudos de pragmática hispânica tiveram como foco os atos de fala e sua realização em uma ou mais variedades do espanhol, ou contrastaram as realizações de um ou mais atos de 
fala, ou mesmo uma das variedades do espanhol com outras línguas. Entretanto, poucos estudos dedicaram-se à variação pragmática especificamente em espanhol. Desta forma, Márquez-Reiter (2002) analisa as estratégias de direticidade e indireticidade (indirectness), bem como de tentativas (tentativeness) para a análise de atos de fala indiretos.

A maioria dos estudos, relatados por Márquez-Reiter, assinala que os possíveis problemas de comunicação entre as variedades são uma decorrência de diferentes sistemas de cortesia, a partir dos quais os falantes latino-americanos tendem a considerar a fala dos espanhóis como muito direta ou mesmo abrupta. Assim como para os espanhóis, os latino-americanos podem ser considerados como excessivamente formais, chegando mesmo a serem considerados como cômicos nas suas estratégias de cortesia. Márquez-Reiter (2002) propõe metodologicamente uma distinção de análise que tem a ver com a codificação das sentenças e a tentativa de atenuação da força ilocutiva dessas sentenças.

A indireticidade atua no nível da estrutura do enunciado, afeta o ato de fala no sentido de que afeta as unidades mínimas a partir das quais o ato de fala é realizado (modo declarativo, interrogativo ou imperativo). A tentativa de atenuação é mais flexível do que a indireticidade, pode aparecer no centro do ato ou nos seus elementos periféricos, podendo modificar o pedido internamente ou externamente pela adição de elementos mitigadores ou pela modificação interna do enunciado, pela graduação ou pelo tipo de escolhas linguísticas ao codificar o ato de fala. A diferença entre indireticidade e tentativa de atenuação é exemplificada pela autora com os seguintes dados do seu corpus (1), (2) e (3).

(1) ¿Podés atender el teléfono mientras salgo a hacer un mandado?

(2) ¿Podés atender el teléfono por favor mientras salgo a hacer un mandadito?

(3) ¿Podrías atenderme el teléfono mientras salgo a hacer un mandado?

Nos três casos, temos um pedido indireto. Entretanto, o fato de o enunciado (2) ter sido mitigado pela partícula discursiva de polidez (por favor) e 
pelo diminutivo (-ito) faz desse enunciado (2) um enunciado mais marcado pela tentativa de atenuação do que o (1). O uso da partícula discursiva "por favor" faz com que o enunciado seja menos coercitivo, mas também assinala que se trata de um ato diretivo. O enunciado (3) também tem maior tentativa de atenuação, pela escolha do condicional, enquanto o indicativo expressa certeza e engajamento com o estado real da situação, o condicional remete a ideia de que a realização do evento em questão depende de algum outro fator.

Enquanto no enunciado (2) as marcas de tentativa de atenuação são modificadores internos de mitigação que se somam ao enunciado, no enunciado (3) as marcas de tentativas de atenuação se dão pela escolha das formas linguísticas que codificam o ato de fala em si. Para a autora, o fato de que alguns desses pedidos indiretos tenham sido estrategicamente mitigados com diferentes sentidos, provavelmente, afeta o valor perlocucionário do enunciado. Os enunciados (1) (2) e (3) tem o mesmo grau de indireticidade pela sua codificação linguística, mas sua percepção performativa em diferentes variedades do espanhol não tem o mesmo impacto. Esses pedidos têm o mesmo grau de indireticidade (convencional), mas não necessariamente o mesmo grau de tentativa (de mitigação ou atenuação da sua forca impositiva).

Os resultados dessas pesquisas mostram que possíveis mal-entendidos pragmáticos podem ocorrer entre falantes de diferentes variedades do espanhol. Em nossa pesquisa, acreditamos que o estilo comunicativo de Assunção e Buenos Aires na formulação de atos diretivos seja mais "indireto" no primeiro caso e mais "direto" no segundo. E nos perguntamos sobre as estratégias de cortesia utilizadas nas cidades de fronteiras, ou seja, se haverá convergência com a capital do Paraguai ou a da Argentina; e se há convergência entre elas, resultante do contato linguístico.

Para Gutiérrez-Rivas (2011), as normas e os valores pragmáticos de cortesia que os falantes percebem como adequados para uma comunidade de fala 
apresentam variações consideráveis, não só entre os falantes de diferentes línguas, mas também entre falantes da mesma língua, e cita autores como BlumKulka et al. (1989), García (1993, 2002, 2007), Koike (1994), Le Pair (1996) e Márquez-Reiter (2000), que atestam que os aspectos sociedade e cultura transcendem as línguas e são extremamente importantes para o estudo da variação pragmática. Ainda segundo Gutiérrez-Rivas (2011), diferentes sociedades têm sido classificadas como mais "deferenciais" ou mais "solidárias" considerando variedades nacionais ou regionais dominantes e não dominantes da mesma língua.

Na cortesia deferencial, prima o traço da hierarquia e da distância, pela indireticidade, enquanto, na cortesia solidária, prima o traço da proximidade e do pertencimento ao mesmo grupo, primando a direticidade. Blum-Kulka et al. (1989) propõe um modelo que mede a (in)direticidade do ato de fala para analisar estratégias de locutores. De acordo com a taxonomia de Blum-Kulka et al. (1989, p. 18), há nove tipos de estratégias que podem ser utilizadas no caso dos atos de fala diretivos: os cinco primeiros são considerados estratégias diretas, as duas seguintes indiretas convencionais e as duas últimas, indiretas não convencionais. 
Quadro 1: Taxonomia de Blum-Kulka et al. (1989) adaptada por Gutiérrez-Rivas (2011)

\begin{tabular}{|c|c|}
\hline Tipo de estratégia e código & Definição \\
\hline $\begin{array}{l}\text { Modo gramatical do verbo } \\
\text { (Mood derivable - 1MD) }\end{array}$ & $\begin{array}{l}\text { Enunciados em que o modo gramatical do verbo indica } \\
\text { a força ilocucionaria }\end{array}$ \\
\hline $\begin{array}{c}\text { Performativas } \\
(\text { Performatives }-2 \mathrm{P}) \\
\end{array}$ & $\begin{array}{c}\text { Enunciados em que a força ilocucionária está } \\
\text { explicitamente expressa }\end{array}$ \\
\hline $\begin{array}{c}\text { Atenuação } \\
\text { (Hedge performatives - 3HP) }\end{array}$ & $\begin{array}{l}\text { Enunciados em que a força ilocucionária é modificada } \\
\text { por um atenuador (ou hedge) }\end{array}$ \\
\hline $\begin{array}{c}\text { Obrigação } \\
\text { (Obligation statements - 4OS) }\end{array}$ & $\begin{array}{c}\text { Enunciados que comprometem ou obrigam o ouvinte a } \\
\text { realizar a ação }\end{array}$ \\
\hline $\begin{array}{c}\text { Desejo } \\
(\text { Want statements - 5WS) }\end{array}$ & $\begin{array}{c}\text { Enunciados que destacam o desejo de que o ouvinte } \\
\text { faça alguma coisa }\end{array}$ \\
\hline $\begin{array}{c}\text { Sugestão } \\
\text { (Suggestory formulae - 6SF) }\end{array}$ & Enunciados que contêm uma sugestão \\
\hline $\begin{array}{l}\text { Condições preparatórias } \\
\text { (Query preparatory - 7QP) }\end{array}$ & $\begin{array}{c}\text { Enunciados com condições preparatórias e } \\
\text { convencionalizadas em qualquer língua específica }\end{array}$ \\
\hline $\begin{array}{c}\text { Referência ao objeto } \\
\text { (Strong hints - 8SH) }\end{array}$ & $\begin{array}{l}\text { Enunciados que fazem referência parcial ao objeto ou } \\
\text { elemento necessário para a implementação do ato }\end{array}$ \\
\hline $\begin{array}{l}\text { Referência ao pedido } \\
\text { (Mild hints }-9 \mathrm{MH})\end{array}$ & $\begin{array}{c}\text { Enunciados que não fazem referência ao pedido, ou a } \\
\text { nenhum de seus elementos, mas que se interpretam } \\
\text { como pedidos pelo contexto. }\end{array}$ \\
\hline
\end{tabular}

Esta taxonomia foi adaptada para o espanhol por Márquez-Reiter (2000), sendo os pedidos divididos por esta autora e mais tarde por Félix-Brasdefer (2011, p. 57-58) em três tipos: a) diretos (verbos com imperativo, modais como "querer" ou "necessitar", b) indiretos convencionais (pergunta preparatória, sugestão) e c) indiretos não convencionais.

O espanhol da Argentina conta com mais descrições pragmáticas que o espanhol do Paraguai, onde o contato entre o espanhol e o guarani promoveu estratégias particulares para construção de enunciados e intenções no âmbito da pragmática. No que se refere ao uso de marcadores de discurso, seu uso vem sendo estudado desde a década de oitenta. Penner, Acosta \& Segovia (2012) descrevem uma sequência de pesquisas sobre partículas discursivas e sua função pragmática na variedade paraguaia do espanhol desde final dos anos 70. Há registros de partículas discursivas produzidas em espanhol, mas que resultam de uma tradução ou adaptação de algum termo do guarani. Entre as partículas 
descritas pelas autoras, algumas estão presente neste trabalho, como o uso de -na e de -un poco, para marcar cortesia. Os estudos consultados para este trabalho demonstram que as normas e os valores pragmáticos de cortesia que os falantes percebem como adequado para uma comunidade de fala apresentam variações consideráveis, não somente entre os falantes de diferentes línguas, mas também entre os de uma mesma língua.

\section{ECOLOGIA DAS LÍNGUAS}

Considerando a Ecolinguística como o estudo da relação entre a língua e o meio-ambiente (Couto, 2007), e como a língua segue em evolução e modificase com os contatos de seus falantes (Mufwene, 2016), buscamos relacionar esse conceito com o contexto de contato entre variedades do espanhol com outras línguas na região da Tríplice Fronteira. Para Couto (2009, p.149), “quando se fala em situações fronteiriças é necessário distinguir àquelas em que há um acidente geográfico separando os dois países e àquelas em que ele inexiste.". No caso da Tríplice fronteira, há um acidente geográfico, ou seja, os rios Paraná e Iguaçu, porém os centros urbanos estão bem conectados por rodovias e pontes, sendo o acesso bastante facilitado em termos de aduanas e controles. Pode-se chegar a qualquer uma das cidades de carro, de ônibus, a pé ou de bicicleta. $\mathrm{O}$ trânsito entre Ciudad del Este e Foz de Iguaçu é o mais intenso nos dias de semana e em período diurno, em comparação ao fluxo entre Foz e Puerto Iguazú, devido a movimentação relacionada ao comércio da cidade paraguaia. O fluxo entre Foz do Iguaçu e Puerto Iguazú é mais intenso nos fins de semana e no período noturno, relacionado à gastronomia da região. O trânsito entre Puerto Iguazú e Ciudad del Este pode ser feito via terrestre, passando por Foz de Iguaçu, ou por meio de balsa pelo rio Iguaçu e cruzando o rio Paraná.

Podemos afirmar que o limite entre Estados não converge com os limites culturais, pois a região de fronteira compartilha hábitos e costumes como ocorre 
na Tríplice Fronteira. Inclusive muitas famílias da região estão compostas por membros dispersos entre as cidades fronteiriças e seus limites nacionais. Desta forma, para Foucher (1991), as fronteiras do Estado moderno surgem com a função de ruptura e descontinuidade geopolítica com o objetivo de separar "o tempo das histórias, das sociedades, das economias dos Estados, das línguas, entre outros". Para o autor, o significado de fronteira "prende-se às estruturas espaciais funcionais que se estabelecem sobre três fatos: o real, o simbólico e o imaginário". Desta forma, como estabelece Rattzel (1990), a fronteira compreende muito mais do que uma demarcação de limite, mas uma região com características em comum.

Este convívio intercultural pode se refletir em convergências linguísticas entre o espanhol, o português e o guarani, porém, esses dados ainda estão sendo pesquisados mais detalhadamente. A regra do bilinguismo, ou plurilinguismo, em que duas ou mais línguas convivem em um território se aplica tanto às duas capitais quanto aos dois centros urbanos da fronteira. No caso desta pesquisa, temos os centros urbanos de Buenos Aires, uma cidade Alfa global ${ }^{3}$ que atrai um notório fluxo migratório, e Assunção, cidade onde a relação do espanhol com o guarani está presente nas interações cotidianas. No caso das cidades fronteiriças de Puerto Iguazú (Argentina) e Ciudad del Este (Paraguai), o fluxo contínuo, as

\footnotetext{
${ }^{3} \mathrm{O}$ termo cidade global designa a cidades que exercem centros de poder, conforme a definição de Hall (1984):

São centros de poder político, tanto nacional como internacional, e de organização governamental; centros de comércio nacional e internacional, agindo como entrepostos para seus países e às vezes para países vizinhos; ainda, centros bancários, de seguros e serviços financeiros em geral; centros de atividade profissional avançada, na medicina, no direito, em estudo avançado, e de aplicação de conhecimento científico na tecnologia; centros de acúmulo de informação e difusão através da mídia de massa; centros de consumo, sejam de artigos de luxo a uma minoria ou de produtos de produção em massa; centros de artes, cultura, entretenimento e de atividades auxiliares relacionadas (HALL, 1984)
}

De acordo com a classificação do Globalization and World Cities Research Network, Buenos Aires enquadra-se na categoria de cidade Alfa - e Assunção, Gamma -: https://www.lboro.ac.uk/gawc/world2020t.html 
relações com o Brasil e com a imigração (árabe, chinesa, coreana, europeia) incrementam o contato linguístico histórico com o guarani nesta região. A migração dos povos leva à diversificação linguística e os contatos linguísticos a fenômenos de convergência. Couto (2009, p. 55) sintetiza os fatores que podem influenciar os diferentes tipos de contatos:

O primeiro fator é a quantidade de pessoas que se deslocam. Se for um grande grupo, tenderão a se manter juntas, dando lugar a uma rede de interações relativamente densa, o que propicia a manutenção ou a imposição da própria língua. O segundo é o tempo de permanência no novo território. Se for por um curto período, praticamente nada (ou muito pouco) acontecerá. (...). Não podemos esquecer também a intensidade do contato, o que, aliás, está intimamente associado a quantidade. Tudo pode ser neutralizado pelo poder econômico, político e militar de cada um dos lados contatantes. (...) Outro fator que pode afetar os resultados do contato são as atitudes dos dois lados. Se o povo imigrante, mesmo sendo um enclave e uma minoria, tiver uma atitude de resistência cultural, poderá fazer com que sua língua e cultura pelo menos demorem a ser assimiladas pela língua e cultura envolventes. Depois de tudo isso, a semelhança/diferença tipológica entre as linguas contatantes pode influir no resultado. (COUTO, 2009, p. 55)

\subsection{Paisagem linguística da Tríplice Fronteira}

Considerando o contato e a ecologia das línguas, trazemos algumas considerações sobre a presença do espanhol e do português neste contexto fronteiriço. Não podemos afirmar que há um equilíbrio entre as duas línguas, pois observamos que o português exerce um papel de poder nesta região, por estar presente e ser usada com frequência nas interações comerciais entre brasileiros e hispano-falantes.

No caso de Puerto Iguazu, na Argentina, devido a distância existente entre esta cidade e Buenos Aires e a dificuldade de alcance de sinais de TV nesta região da província de Misiones até pouco tempo atrás, observava-se que o contato com o português se dava no consumo de programação da TV brasileira. Além disso, atualmente, devido ao grande fluxo de turistas brasileiros, o português se vê 
refletido nas vitrines do comércio local e na fala dos comerciantes locais, compondo assim a paisagem linguística da cidade. Nas figuras 1 e 2 vemos uma placa de entrada para um local de compras de produtos alimentícios conhecido como La Feirinha, e letreiros de diferentes lojas no centro da cidade.
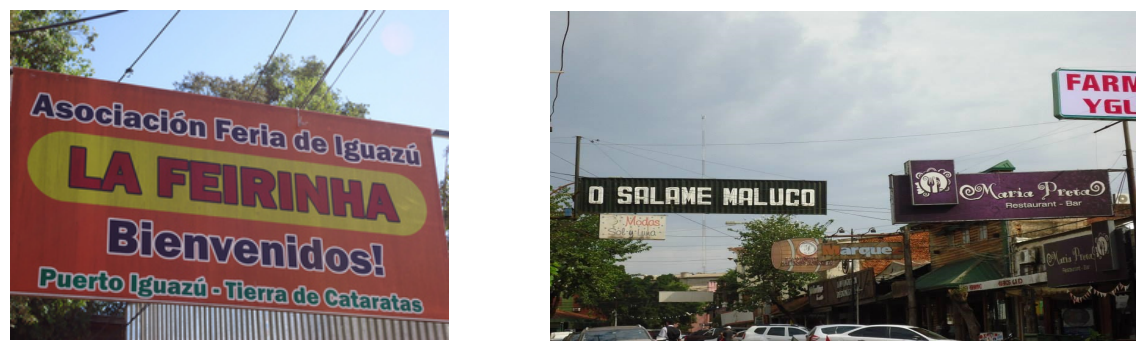

Figs. 1 e 2: presença do português nos letreiros de espaços frequentados por turistas brasileiros na cidade de Puerto Iguazú.

Ciudad del Este, no Paraguai, também mantém uma relação com o português em seu comércio, por conta do fluxo de turistas e também pela grande quantidade de brasileiros que vivem na cidade (comerciantes, estudantes de cursos de medicina, e proprietários rurais, por exemplo). Conforme observamos na figura 3, o português está presente no comércio de rua da cidade, alternando a transmissão de informações com o espanhol.

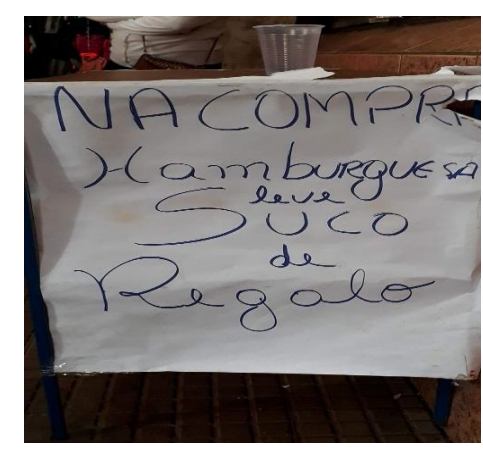

Fig. 3: Cartaz de comércio informal de Ciudad del Este, contendo informações em português e em espanhol.

Se comparamos essa ecologia presente nas duas cidades com Foz do Iguaçu, percebemos que o espanhol não possui a mesma influência em território 
brasileiro. Nota-se algumas poucas traduções em menus de restaurantes e vitrines de lojas, especialmente nos espaços em que se recebem turistas. Mas, a quantidade de pessoas que entende e fala o espanhol é bem menor que aquela que se comunica em português em Puerto Iguazú e Ciudad del Este. Mesmo assim, podemos ilustrar a presença do espanhol em determinados espaços da cidade, como nas figuras 4 e 5, que ilustram respectivamente uma notícia local relacionada ao Paraguai e um anúncio em um shopping próximo à aduana argentina e que recebe muitos turistas desse país.
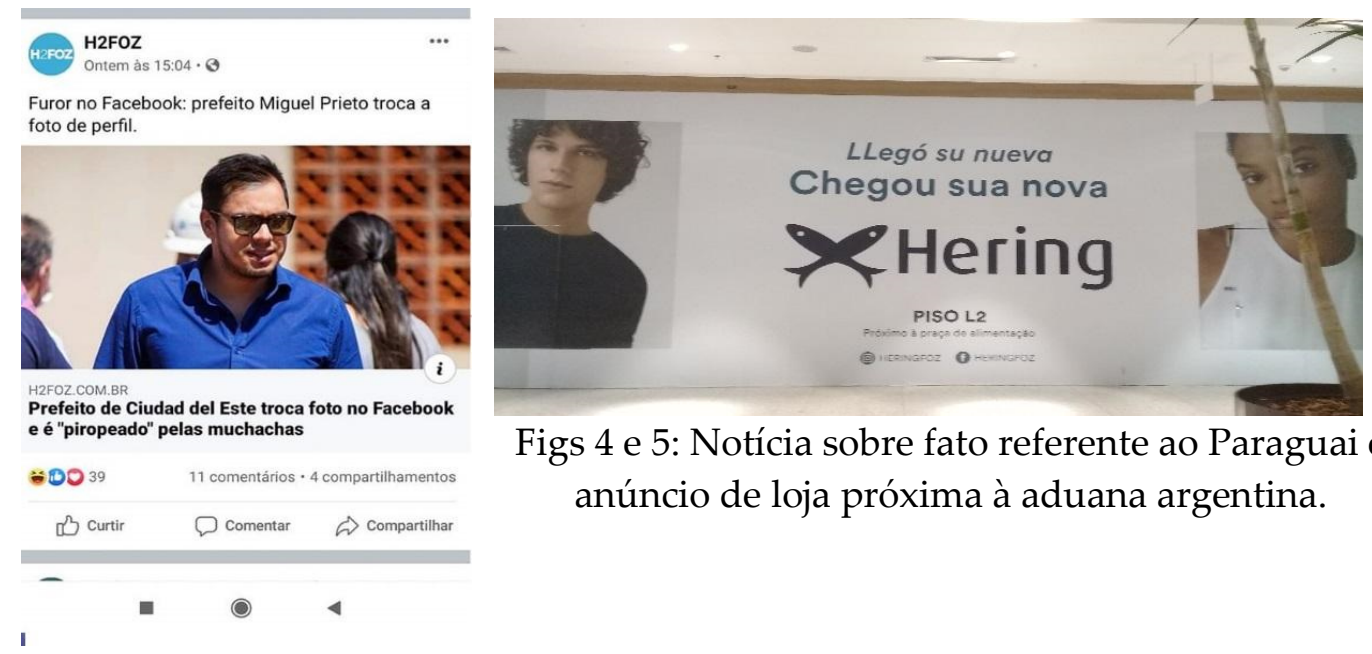

Figs 4 e 5: Notícia sobre fato referente ao Paraguai e anúncio de loja próxima à aduana argentina.

\section{METODOLOGIA DE ANÁLISE}

A coleta de dados de áudio foi realizada a partir da interação da pesquisadora com quatro participantes, de forma individual - dois homens e duas mulheres - de cada localidade: Assunção e Ciudad del Este, no Paraguai; e Buenos Aires e Puerto Iguazú, na Argentina. Todos os participantes são jovens, com idades compreendidas entre 20 e 35 anos e moradores das cidades mencionadas.

Os enunciados produzidos correspondem a duas situações de interação: Sacarle una (la) foto a alguien (e variações verbais) e Cerrar la puerta, e foram interpretados a partir das instruções fornecidas conforme o quadro 2. 
Quadro 2: contextos de Interação 1 e 2 para ato de fala pedido

\begin{tabular}{|l|l|l|}
\cline { 2 - 3 } \multicolumn{1}{c|}{} & \multicolumn{2}{c|}{ Interação 1 e 2 } \\
\hline \multirow{5}{*}{ INVESTIGADOR } & Situações & $\begin{array}{l}\text { 1) Pedile que te saque una foto. } \\
\text { 2) Pedile que cierre la puerta. }\end{array}$ \\
\cline { 2 - 3 } & Contextos & $\begin{array}{l}\text { 1) Siguen el paseo y ves un lugar hermoso, en } \\
\text { dónde querés que te saquen una foto. Pedile a } \\
\text { María que te saque una foto: } \\
\text { 2) Al día siguiente, están en la clase y hay mucho } \\
\text { ruido afuera. } \\
\text { Pedile a Pedro que cierre la puerta: }\end{array}$ \\
\hline INFORMANTE & Enunciado meta & $\begin{array}{l}\text { 1) Sacame una foto. } \\
\text { 2) Cerrá la puerta. }\end{array}$ \\
\hline
\end{tabular}

Os contextos foram pensados para uso em tratamento igualitário, ou seja, dirigidos a pessoas próximas, do convívio social do informante (KEBRATORECCHIONI, 2006).

Para realizar a análise pragmática variacional, consideramos todas as variações de enunciados produzidos pelos participantes (o uso de estratégias de atenuação e/ou intensificação do ato de fala, bem como estratégias de indireticidade) a partir dos contextos padrões: sacar la/una foto e cerrar la puerta, o que gerou um total de 117 enunciados.

Os enunciados foram analisados, destacando a quantidade de ocorrências das estratégias de variação pragmática em cada tipo de enunciado (de núcleo foto e de núcleo puerta). Essa etapa da análise foi realizada manualmente, observando cada um dos 117 enunciados produzidos. As ocorrências quantificadas foram classificadas de acordo com 8 estratégias de atenuação ou intensificação da força ilocucionária do enunciado (quadro 3). 
Quadro 3: estratégias de atenuação ou intensificação da força ilocucionária do enunciado e respectivas siglas.

\begin{tabular}{|l|c|}
\hline \multicolumn{1}{|c|}{$\begin{array}{c}\text { Estratégias de atenuação ou intensificação da força ilocucionária do } \\
\text { enunciado }\end{array}$} & Sigla \\
\hline Modo da frase ou enunciado escolhido (declarativo, interrogativo, imperativo) & $\mathrm{E}$ \\
\hline $\begin{array}{l}\text { Modalização do ato de fala pela seleção de tempos, modos ou aspectos verbais } \\
\text { (perífrases, condicional) }\end{array}$ & $\mathrm{V}$ \\
\hline Formas Nominais & $\mathrm{FN}$ \\
\hline Partículas Discursivas & $\mathrm{PD}$ \\
\hline Advérbios & $\mathrm{ADV}$ \\
\hline Ordenamento Sintático & SIN \\
\hline Atos de fala preparatórios & $\mathrm{AF}$ \\
\hline Deslocamento acentual para a esquerda (ênfase) & $\mathrm{AC}$ \\
\hline
\end{tabular}

Com a distribuição do total de estratégias utilizadas pelos participantes, pudemos comparar os usos mais frequentes em cada variedade do espanhol e em cada contexto.

Os 117 enunciados também foram classificados de acordo com 9 estratégias de indireticidade dos atos de fala, considerando a escala de 1 a 9 propostas por Blum-Kulka, House \& Kasper (1989) e apresentadas no quadro 1.

Os dados quantificados foram distribuídos manualmente para os dois diferentes tipos de enunciados (núcleo foto vs núcleo puerta), nas quatro diferentes localidades (Assunção, Buenos Aires, Ciudad del Este e Puerto Iguazú).

\section{RESULTADOS}

No ato de fala diretivo pedido, o locutor realiza um ato iniciativo, ou seja, um pedido de ação ao seu interlocutor. A cortesia requer diferentes estratégias de atenuação do ato de fala diretivo, ameaçador das faces dos interlocutores, tanto para quem solicita como para quem se solicita a ação. Neste contexto, realizamos a análise da variação pragmática na sua realização lexical 
considerando 8 estratégias de atenuação ou intensificação da força ilocucionária do enunciado e 9 estratégias de indireticidade dos atos de fala.

\subsection{Atenuação ou intensificação da força ilocucionária}

\section{- Assunção (PY):}

Descrevemos as variações de 33 enunciados, produzidas para o ato de fala pedido a partir dos 21 enunciados imperativos e dos 12 enunciados interrogativos. No quadro 4, apresentamos as estratégias de variação pragmática para as 12 realizações do enunciado imperativo Sacame una foto, considerando os componentes linguísticos na seleção lexical. Nas produções realizadas pelos locutores de Assunção, observamos o uso preferido do verbo sacar (9), variando com o uso do verbo quitar (3). As 12 realizações do objeto são indeterminadas: una foto (informação nova). Houve 16 modificações na forca ilocucionária do ato de fala: 2 modificações com formas nominais de tratamento (FN): María e 14 modificações com partícula discursiva (PD): na (7), ey (4) e un poco (3).

Quadro 4: ato de fala pedido modo imperativo de locutores de Assunção - foto.

\begin{tabular}{|c|c|}
\hline Enunciado imperativo & Ocorrências \\
\hline Quitame una foto & 3 \\
\hline María, sacamena un poco una foto & 2 \\
\hline Ey, sacamena una foto & 2 \\
\hline Sacamena una foto & 2 \\
\hline Ey, sacame una foto & 2 \\
\hline Sacamena un poco una foto & 1 \\
\hline TOTAL & $\mathbf{1 2}$ \\
\hline
\end{tabular}

A partícula na, que acompanha sacame, é de origem guarani e está presente em alguns dos enunciados produzidos no modo imperativo. Aparece em situações de pedidos, conforme exemplificado em Zarratea \& Acosta (2013)4,

\footnotetext{
${ }^{4}$ ZARRATEA, T.; ACOSTA, F. Avane'e. Manual para leer y escribir en Guarani. Asunción: Servilibro, 2013.
} 
representando uma partícula (sufixo) de rogo. Além disso, na maioria das vezes, está acompanhada da estrutura un poco, como no enunciado Sacamena un poco una foto. Segundo Galeano Olivera (1999), há um sufixo em guarani mi que se traduz por un poco em espanhol: “É praticamente impossível encontrar um compatriota que deixe de utilizar em sua locução diária expressões como 'vení un poco' (venha um pouco), 'prestame un poco' (me empresta um pouco) e 'decile un poco' (sic) (diga-lhe um pouco. Tradução nossa) $)^{\prime \prime}$.

Este modismo tem diversos usos, geralmente vinculados com a expresión ' $n a$ ' en guarani. Utilizado como por favor, muitas vezes. Assim, poderíamos substituir o modismo 'un poco' diretamente com la utilização de por favor (...) (RUBINSZTEIN, 2013, p. 47. Tradução nossa) ${ }^{6}$.

Na realização do ato de fala pedido com foto, registramos 16 modificações do ato de fala pedido em 12 enunciados, o que mostra um alto grau de trabalho de face. Esse grau de trabalho de face parece ser ainda mais alto com o enunciado puerta.

No quadro 5, apresentamos as estratégias de variação pragmática para as 9 realizações de enunciado interrogativo para Sacame una foto, considerando os componentes linguísticos na seleção lexical. Observamos o uso do verbo sacar (3) variando com o uso preferido do verbo quitar (6). As 9 realizações do objeto são indeterminadas: una foto (informação nova). Houve 10 modificações na força ilocucionária do ato de fala: 9 modificações aspectuais relacionadas à forma verbal (V): poder+infinitivo, perífrase de aspecto inicial e 1 (uma) modificação com forma nominal de tratamento (FN): María.

\footnotetext{
${ }^{5}$ Es practicamente imposible encontrar un compatriota que deje de utilizar en su locución diaria expresiones como 'vení un poco', 'llevale un poco', 'prestame un poco' y 'decile un poco' (sic).

${ }^{6}$ Este modismo tiene diversas utilizaciones, quizás vinculadas con la expresión 'na' en guarani. Utilizado como por favor, muchas veces. Así, podríamos reemplazar el modismo 'un poco' directamente con la utilización del por favor (...) RUBINSZTEIN, Natalio. Modismos paraguayos. Glosario por Natalio y vos. 3a. ed. Asuncion: Criterio Ediciones, 2013.
} 
Quadro 5: ato de fala pedido modo interrogativo de locutores de Assunção - foto.

\begin{tabular}{|c|c|}
\hline Enunciado interrogativo & Ocorrências \\
\hline ¿ Me podés sacar una foto? & 3 \\
\hline ¿ Me podés quitar una foto? & 3 \\
\hline ¿María, me podés quitar una foto? & 3 \\
\hline TOTAL & $\mathbf{9}$ \\
\hline
\end{tabular}

No quadro 6, apresentamos as estratégias de variação pragmática para as 9 realizações do enunciado imperativo Cerrá la puerta, considerando os componentes linguísticos na seleção lexical. Houve 6 modificações na força ilocucionária do ato de fala: 3 modificações com formas nominais de tratamento (FN): Pedro; 2 modificações com partícula discursiva (PD): por favor e 1 (uma) modificação por ordenamento sintático (SIN): pronome clítico ético -me.

Quadro 6: ato de fala pedido modo imperativo de locutores de Assunção - puerta.

\begin{tabular}{|c|c|}
\hline Enunciado imperativo & Ocorrências \\
\hline Cerrá la puerta & 6 \\
\hline Pedro, cerrá la puerta, por favor & 2 \\
\hline Pedro, cerrame la puerta & 1 \\
\hline TOTAL & 9 \\
\hline
\end{tabular}

No quadro 7, apresentamos as estratégias de variação pragmática para as 3 realizações de enunciados interrogativos Cerrá la puerta, considerando os componentes linguísticos na seleção lexical. Houve 1 (uma) modificação na força ilocucionária do ato de fala e 1 (uma) modificação aspectual relacionada à forma verbal (V): "poder+infinitivo" perífrase de aspecto inicial.

Quadro 7: ato de fala pedido modo interrogativo de locutores de Assunção - puerta.

\begin{tabular}{|c|c|}
\hline Enunciado interrogativo & Ocorrências \\
\hline ¿Podés cerrar la puerta? & 3 \\
\hline TOTAL & 3 \\
\hline
\end{tabular}


- Buenos Aires (AR):

Nesta seção, descrevemos as variações de 27 enunciados interrogativos produzidos. No Quadro 8, apresentamos as estratégias de variação pragmática para as 12 realizações de enunciado interrogativo para Sacame una foto, considerando os componentes linguísticos na seleção lexical. Observamos o uso exclusivo do verbo sacar (12). As 12 realizações do objeto são indeterminadas: una foto (informação nova). Houve 4 modificações na força ilocucionária do ato de fala: 1 (uma) modificação com formas nominais de tratamento (FN): Pedro e 3 modificações pela seleção de tempo e modo verbal (V): uso do condicional me sacarías.

Quadro 8: ato de fala pedido modo interrogativo de locutores de Bs. Aires - foto.

\begin{tabular}{|c|c|}
\hline Enunciado interrogativo & Ocorrências \\
\hline ¿Me sacás una foto? & 9 \\
\hline ¿Me sacarías una foto? & 2 \\
\hline ¿Pedro, me sacarías una foto? & 1 \\
\hline TOTAL & $\mathbf{1 2}$ \\
\hline
\end{tabular}

No quadro 9, apresentamos as estratégias de variação pragmática para as 15 realizações de enunciados interrogativos para Cerrá la puerta, considerando os componentes linguísticos na seleção lexical. Houve 13 modificações na força ilocucionária do ato de fala: 2 modificações com formas nominais de tratamento (FN): Pedro; 6 modificações pela seleção de tempo e modo verbal ou aspecto (V): uso do condicional cerrarías (3) e uso da perífrase de aspecto inicial poder + infinitivo (3); 3 modificações por ordenamento sintático (SIN): uso do pronome dativo ético ou de interesse: me + cerrar e 2 modificações da força ilocucionária por advérbio de negação. (ADV): no?. 
Quadro 9: ato de fala pedido modo interrogativo de locutores de Bs. Aires - puerta.

\begin{tabular}{|c|c|}
\hline Enunciado interrogativo & Ocorrências \\
\hline ¿Cerrás la puerta? & 8 \\
\hline ¿Podés cerrar la puerta? & 2 \\
\hline ¿Pedro, me cerrarías la puerta? & 1 \\
\hline ¿Pedro, cerrarías la puerta? & 1 \\
\hline ¿Me cerrarías la puerta? & 1 \\
\hline ¿No me cerrás la puerta? & 1 \\
\hline ¿No podés cerrar la puerta? & 1 \\
\hline TOTAL & $\mathbf{1 5}$ \\
\hline
\end{tabular}

- Ciudad del Este (PY):

Nesta seção, descrevemos as variações de enunciados a partir dos 10 enunciados imperativos e dos 12 enunciados interrogativos. No quadro 10, apresentamos as estratégias de variação pragmática para as 6 realizações do enunciado imperativo Sacame una foto, considerando os componentes linguísticos na seleção lexical. Há variação entre a seleção do verbo sacar (3) com o uso do verbo quitar (3). As 6 realizações do objeto são indeterminadas: una foto (informação nova), e há 2 modificações com formas nominais de tratamento (FN): María.

Quadro 10: ato de fala pedido modo imperativo de locutores de Cd. del Este - foto.

\begin{tabular}{|c|c|}
\hline Enunciado imperativo & Ocorrências \\
\hline Quitame una foto & 3 \\
\hline María sacá una foto & 1 \\
\hline María, sacame una foto & 1 \\
\hline Sacame una foto & 1 \\
\hline TOTAL & $\mathbf{6}$ \\
\hline
\end{tabular}

No quadro 11, apresentamos as estratégias de variação pragmática para as 6 realizações de enunciado interrogativo para Sacame una foto, considerando os componentes linguísticos na seleção lexical. Há variação entre a seleção do verbo sacar (3) com o uso do verbo quitar (3). Houve 3 modificações na força ilocucionária do ato de fala: 3 modificações aspectuais relacionadas a forma verbal (V): poder+infinitivo, perífrase de aspecto inicial. 
Quadro 11: ato de fala pedido modo interrogativo de locutores de Cd. del Este - foto.

\begin{tabular}{|c|c|}
\hline Enunciado interrogativo & Ocorrências \\
\hline ¿Me podés sacar una foto? & 3 \\
\hline ¿Me quitás una foto? & 3 \\
\hline TOTAL & $\mathbf{6}$ \\
\hline
\end{tabular}

No quadro 12, apresentamos as estratégias de variação pragmática para as 4 realizações de enunciados imperativos Cerrá la puerta, considerando os componentes linguísticos na seleção lexical. Não houve modificação na forca ilocucionária do ato de fala.

Quadro 12: ato de fala pedido modo imperativo de locutores de Cd. del Este - puerta.

\begin{tabular}{|c|c|}
\hline Enunciado imperativo & Ocorrências \\
\hline Cerrá la puerta & 4 \\
\hline TOTAL & 4 \\
\hline
\end{tabular}

No quadro 13, apresentamos as estratégias de variação pragmática para as 6 realizações de enunciados interrogativos para Cerrá la puerta, considerando os componentes linguísticos na seleção lexical. Houve 6 modificações na força ilocucionária do ato de fala: 6 modificações aspectuais relacionadas a forma verbal (V): poder+infinitivo perífrase de aspecto inicial.

Quadro 13: ato de fala pedido modo interrogativo de locutores de Cd. del Este - puerta.

\begin{tabular}{|c|c|}
\hline Enunciado interrogativo & Ocorrências \\
\hline ¿Podés cerrar la puerta? & 6 \\
\hline TOTAL & 6 \\
\hline
\end{tabular}

\section{- Puerto Iguazú (AR):}

Nesta seção, descrevemos as variações de 33 enunciados, sendo 21 enunciados imperativos e 12 enunciados interrogativos. No quadro 14, apresentamos as estratégias de variação pragmática para as 12 realizações do enunciado imperativo Sacame una foto, considerando os componentes linguísticos na seleção lexical. Houve 1 (uma) modificação na força ilocucionária do ato de 
fala: 1 (uma) modificação no ordenamento sintático (SIN): "clítico 0" mudança de regime verbal do verbo pelo apagamento do pronome clítico sacarle una foto a alguien versus sacar una foto, como estratégia de intensificação da urgência do ato de fala pelo apagamento dos participantes do evento.

Quadro 14: ato de fala pedido modo imperativo de locutores de Pto Iguazú- foto.

\begin{tabular}{|c|c|}
\hline Enunciado imperativo & Ocorrências \\
\hline Sacame una foto & 9 \\
\hline Sacá una foto & 3 \\
\hline TOTAL & $\mathbf{1 2}$ \\
\hline
\end{tabular}

No quadro 15, apresentamos as estratégias de variação pragmática para as 6 realizações de enunciado interrogativo para Sacame una foto, considerando os componentes linguísticos na seleção lexical. Houve 3 modificações na força ilocucionária: 3 modificações pela seleção de tempo e modo verbal ou aspecto (V): uso do condicional sacarías.

Quadro 15: ato de fala pedido modo interrogativo de locutores de Pto. Iguazú - foto.

\begin{tabular}{|c|c|}
\hline Enunciado interrogativo & Ocorrências \\
\hline ¿Me sacarías una foto? & 3 \\
\hline ¿Me sacás una foto? & 3 \\
\hline TOTAL & 6 \\
\hline
\end{tabular}

No quadro 16, apresentamos as estratégias de variação pragmática para as 9 realizações do enunciado imperativo Cerrá la puerta, considerando os componentes linguísticos na seleção lexical. Houve 1 (uma) modificação na força ilocucionária: 1 (uma) modificação por partícula discursiva (PD): che.

Quadro 16: ato de fala pedido modo imperativo de locutores de Pto. Iguazú - puerta.

\begin{tabular}{|c|c|}
\hline Enunciado imperativo & Ocorrências \\
\hline Cerrá la puerta & 6 \\
\hline Che, cerrá la puerta & 3 \\
\hline TOTAL & $\mathbf{9}$ \\
\hline
\end{tabular}


No quadro 17, apresentamos as estratégias de variação pragmática para as 6 realizações de enunciados interrogativos para Cerrá la puerta, considerando os componentes linguísticos na seleção lexical. Houve 6 modificações na força ilocucionária: 3 modificações aspectuais relacionadas a forma verbal (V): poder+infinitivo perífrase de aspecto inicial e 3 modificações por partícula discursiva (PD): por favor.

Quadro 17: ato de fala pedido modo interrogativo de locutores de Pto. Iguazú puerta.

\begin{tabular}{|c|c|}
\hline Enunciado interrogativo & Ocorrências \\
\hline ¿Cerrás la puerta? & 3 \\
\hline ¿Podés cerrar la puerta por favor? & 3 \\
\hline TOTAL & $\mathbf{6}$ \\
\hline
\end{tabular}

\subsection{Grau de indireticidade}

No nível de análise do grau de indireticidade, no caso de foto, há mais indireticidade entre os locutores de Buenos Aires, já que todos realizaram o ato de fala apenas com enunciados interrogativos, forma de enunciado (E) mais indireta do que o imperativo. No caso de puerta, o grau de indireticidade é menor apenas em Assunção. Porém, considerando as estratégias de atenuação ou intensificação, observamos que o grau de indireticidade ${ }^{7}$ é alto em todas as cidades.

\footnotetext{
${ }^{7}$ O grau de indireticidade é o resultado obtido pelo somatório dos enunciados multiplicados pelo valor da estratégia de indireticidade correspondente, de acordo com a taxonomia de Blum-Kulka et al. (1989) e dividido pelo total de enunciados por variedade da língua:
}

Número de enunciados $x$ estratégia de indireticidade

Total de enunciados 
Quadro 18: grau de indireticidade para ato de fala pedido com núcleo foto.

\begin{tabular}{|c|c|c|c|c|}
\hline \multirow[b]{2}{*}{$\begin{array}{l}\text { Estratégias de } \\
\text { Indireticidade }\end{array}$} & \multicolumn{4}{|c|}{ Ato de Fala: Pedido foto N=63 Enunciados } \\
\hline & $\begin{array}{l}\text { Assunção (py) } \\
21 \text { enunciados }\end{array}$ & $\begin{array}{c}\text { Buenos Aires } \\
\text { (ar) } \\
12 \text { enunciados }\end{array}$ & $\begin{array}{c}\text { Ciudad del } \\
\text { Este (py) } \\
12 \text { enunciados }\end{array}$ & $\begin{array}{l}\text { Puerto Iguazú } \\
\qquad(\text { ar }) \\
18 \text { enunciados }\end{array}$ \\
\hline $\begin{array}{l}\text { 1. Modo } \\
\text { gramatical do } \\
\text { verbo }\end{array}$ & 12 imperativos & 0 imperativos & 6 imperativos & $\begin{array}{c}12 \\
\text { imperativos }\end{array}$ \\
\hline 2.Performativs & - & - & - & - \\
\hline 3. Atenuação & - & - & - & - \\
\hline 4. Obrigação & - & - & - & - \\
\hline 5. Desejo & - & $\begin{array}{l}2 \text { negação + } \\
\text { int. }(2 \times 5=10)\end{array}$ & - & - \\
\hline \multirow{2}{*}{ 6. Sugestão } & $\begin{array}{c}9 \\
\text { interrogativos } \\
(9 \times 6=\mathbf{5 4})\end{array}$ & \multirow{2}{*}{$\begin{array}{l}12 \\
\text { interrogativos } \\
(12 \times 6=72)\end{array}$} & $\begin{array}{c}6 \\
\text { interrogativos } \\
(6 \times 6=36) \\
\end{array}$ & \multirow{2}{*}{$\begin{array}{c}6 \\
\text { interrogativos } \\
(6 \times 6=36)\end{array}$} \\
\hline & $\begin{array}{c}9 \text { perífrasis } \\
\text { poder }(9 \times 6=54)\end{array}$ & & $\begin{array}{c}3 \text { perífrasis } \\
\text { poder }(3 \times 6=18)\end{array}$ & \\
\hline $\begin{array}{l}\text { 7. Condições } \\
\text { preparatórias }\end{array}$ & & $\begin{array}{c}3 \text { condicional } \\
(3 \times 7=21)\end{array}$ & - & $\begin{array}{c}3 \text { condicional } \\
(3 \times 7=\mathbf{2 1})\end{array}$ \\
\hline $\begin{array}{l}\text { 8. Referência } \\
\text { ao objeto }\end{array}$ & - & & & \\
\hline $\begin{array}{l}\text { 9. Referência } \\
\text { ao pedido }\end{array}$ & - & - & - & - \\
\hline Total & 120 & 103 & 60 & 69 \\
\hline $\begin{array}{c}\text { Grau de } \\
\text { indireticidade }\end{array}$ & $\begin{array}{c}5,7 \\
(120 / 21) \\
\end{array}$ & $\begin{array}{c}8,6 \\
(103 / 12) \\
\end{array}$ & $\begin{array}{c}5,0 \\
(60 / 12) \\
\end{array}$ & $\begin{array}{c}3,8 \\
(69 / 18) \\
\end{array}$ \\
\hline
\end{tabular}

No caso de foto, há mais de indireticidade entre os locutores de Buenos Aires (quadro 18), já que todos realizaram o ato de fala apenas com enunciados interrogativos, forma de enunciado (E) mais indireta que o imperativo. Grau de indireticidade para o ato de fala pedido: 9 em Buenos Aires, 6 em Assunção, 5 em Ciudad del Este e 4 em Puerto Iguazú. 


\begin{tabular}{|c|c|c|c|c|}
\hline \multirow[b]{2}{*}{$\begin{array}{l}\text { Estratégias de } \\
\text { indireticidade }\end{array}$} & \multicolumn{4}{|c|}{ Ato de Fala: Pedido puerta N=54 Enunciados } \\
\hline & $\begin{array}{l}\text { Assunção (py) } \\
12 \text { enunciados }\end{array}$ & $\begin{array}{l}\text { Buenos Aires } \\
\text { (ar) } \\
15 \text { enunciados }\end{array}$ & $\begin{array}{c}\text { Ciudad del } \\
\text { Este (py) } \\
12 \text { enunciados }\end{array}$ & $\begin{array}{l}\text { Puerto Iguazú } \\
\quad \text { (ar) } \\
15 \text { enunciados }\end{array}$ \\
\hline $\begin{array}{l}\text { 1.Modo } \\
\text { gramatical do } \\
\text { verbo }\end{array}$ & 9 imperativos & 0 imperativos & 4 imperativos & 9 imperativos \\
\hline 2.Performativas & - & - & - & - \\
\hline 3. Atenuação & - & - & - & - \\
\hline 4. Obrigação & - & - & - & - \\
\hline 5. Desejo & - & $\begin{array}{l}2 \text { negação + } \\
\text { int. }(2 \times 5=10)\end{array}$ & - & - \\
\hline \multirow[t]{2}{*}{ 6. Sugestão } & $\begin{array}{c}3 \\
\text { interrogativos } \\
(3 \times 6=18) \\
\end{array}$ & $\begin{array}{c}15 \\
\text { interrogativos } \\
(15 \times 6=90)\end{array}$ & $\begin{array}{c}6 \\
\text { interrogativos } \\
(6 \times 6=36)\end{array}$ & $\begin{array}{c}6 \\
\text { interrogativos } \\
(6 \times 6=36) \\
\end{array}$ \\
\hline & $\begin{array}{c}3 \text { perífrasis } \\
\text { poder }(3 \times 6=18)\end{array}$ & $\begin{array}{c}3 \text { perífrasis } \\
\text { poder }(3 \times 6=18)\end{array}$ & $\begin{array}{c}6 \text { perífrasis } \\
\text { poder }(6 \times 6=36)\end{array}$ & $\begin{array}{c}3 \text { perífrasis } \\
\text { poder }(3 \times 6=18)\end{array}$ \\
\hline $\begin{array}{l}\text { 7.Condições } \\
\text { preparatórias }\end{array}$ & & $\begin{array}{c}3 \text { condicional } \\
(3 \times 7=21)\end{array}$ & & \\
\hline $\begin{array}{l}\text { 8. Referência ao } \\
\text { objeto }\end{array}$ & - & & - & \\
\hline $\begin{array}{l}\text { 9. Referência ao } \\
\text { pedido }\end{array}$ & - & - & - & - \\
\hline $\begin{array}{c}\text { Total de } \\
\text { estratégias }\end{array}$ & 45 & 139 & 76 & 63 \\
\hline $\begin{array}{c}\text { Grau de } \\
\text { indireticidade }\end{array}$ & $\begin{array}{c}3,8 \\
(45 / 12)\end{array}$ & $\begin{array}{c}\mathbf{1 1 , 6} \\
(139 / 12)\end{array}$ & $\begin{array}{c}7,6 \\
(76 / 10)\end{array}$ & $\begin{array}{c}4,2 \\
(63 / 15)\end{array}$ \\
\hline
\end{tabular}

No caso de puerta (quadro 19), o grau de indireticidade é menor apenas em Assunção. Em Buenos Aires, o grau de indireticidade chega a 12, considerando as realizações interrogativas, as formas de sugestão, as declarações de desejo, e os atos de fala preparatórios com condicionais. Em Ciudad del Este, o grau de indireticidade é 8, e em Puerto Iguazú e Assunção, 4. 


\section{CONSIDERAÇÕES FINAIS}

O pedido é um ato de fala iniciativo, com alto grau de imposição do locutor sobre o ouvinte em termos de custo inter-relacional, porém o locutor não tem posição de autoridade sobre o ouvinte ao realizá-lo. Como resultado de nossas análises, no nível da seleção lexical, encontramos variação entre as cidades do Paraguai e as da Argentina para o verbo referente à ação de tirar uma foto. Nas duas cidades argentinas, a única opção possível foi com o uso do verbo sacar, enquanto nas duas cidades do Paraguai, se repete a variação entre sacar e quitar uma foto.

No nível das estratégias de atenuação e intensificação dos atos de fala, encontramos realizações convergentes entre as quatro cidades. O conjunto de estratégias de atenuação e de intensificação do ato de fala pedido é bastante complexo. Para o enunciado foto, os locutores de todas as localidades atenuam a força ilocucionária do ato de fala com estratégias Verbais (V), e três localidades convergem no uso das Formas nominais de tratamento (FN) como estratégia de atenuação, a identificação do outro. A cidade de Buenos Aires é a única a usar apenas enunciados (E) interrogativos para a realização do ato de fala, enquanto as outras três cidades alternam entre os modos imperativo e interrogativo. Com relação ao enunciado (E) puerta, Buenos Aires é a única cidade a realizar o ato de fala pedido apenas com enunciados interrogativos e não com enunciados imperativos em alternância com interrogativos. Para o enunciado puerta, há uma maior necessidade de atenuação do que para foto, dado este que converge nas duas cidades argentinas. Entretanto, nas duas cidades paraguaias, a necessidade de atenuação de puerta foi menor do que a de foto. Assim como para foto, no ato de fala pedido a estratégia mais frequente de atenuação foi a Verbal (V).

Quanto ao grau de indireticidade, podemos afirmar que há diferenças entre as localidades. A variedade de Buenos Aires não possui um sistema mais 
direto, como sugerimos em nossas hipóteses, com relação ao ato de fala diretivo pedido. Esta variedade destaca-se pelo maior grau de atenuação, por apresentar estratégias divergentes das demais variedades do espanhol analisadas. No que se refere à região de fronteira, observamos uma maior convergência de Puerto Iguazú com Ciudad del Este, que com Buenos Aires, que indica o contato linguístico entre essas duas variedades do espanhol e, consequentemente a representação de uma mesma variedade dialetal.

Portanto, podemos considerar que o contraste encontrado entre Buenos Aires e as demais localidades possa refletir-se em possíveis mal-entendidos pragmáticos, como os citados em Márquez-Reiter (2002). De qualquer modo, temos prevista, como proposta futura, a aplicação de testes de percepção, ampliando a pesquisa já iniciada em Figueiredo (2018), para avaliar com mais detalhes o reconhecimento dos falantes quanto à produção dos atos de fala em diferentes variedades do espanhol. Posteriormente, planejamos também elaborar testes de percepção dos atos de fala em espanhol para avaliar o reconhecimento por parte de estudantes brasileiros aprendizes de espanhol como língua adicional na Universidade Federal da Integração Latino-americana (UNILA).

\section{REFERÊNCIAS}

AUSTIN, J.L. How to do things with words. Oxford: University Press, 1962.

BLUM-KULKA, S. Playing it safe: the role of conventionality in indirectness. In: BLUMKULKA, S.; HOUSE, J.; KASPER, G. (eds.). Cross-cultural pragmatics: requests and apologies. Norwood, NJ: Ablex, 1989. p. 37-70.

COUTO, H. H. do. Ecolinguística: estudo das relações entre língua e meio ambiente. Brasilia: Thesaurus, 2007.

Paulo: Contexto, 2009.

- Linguística, ecologia e ecolinguística: contato de línguas. São

FÉLIX-BRASDEFER, C. Cortesia, prosodia y variacion pragmatica en las peticiones de estudiantes universitarios mexicanos y dominicanos. In: GARCIA, C.; PLACENCIA, M. E. Estudios de variación pragmática en español. Buenos Aires. Dunken: 2011. 
FIGUEIREDO, N. dos S. Variação pragmática e ecologia das línguas: análise multimodal de atos de fala no espanhol do Paraguai e da Argentina. 2018. 304 f. Tese. (Doutorado em Letras Neolatinas, Língua Espanhola) Faculdade de Letras, Universidade Federal do Rio de Janeiro, Rio de Janeiro.

FOUCHER, M. Fronts et frontiers: un tour du monde géopolitique. Paris: Fayard, 1991.

GARCÍA, C. Making a request and responding to it: a case study of Peruvian Spanish speakers. In: Journal of Pragmatics 19, [S1], p. 127-52, Feb., 1993.

La expresión de camaradería y solidaridad: cómo los venezolanos solicitan un servicio y responden a la solicitud de un servicio. In: PLACENCIA, M. E.; Bravo, D. (eds.). Actos de habla y cortesía en español. Munich: Lincom, 2002. p. 55-88.

Ché, mirá, vos sabés que no voy a poder: How Argentineans refuse an invitation. In: Hispania 90, n. 3, p. 551-64, Sep., 2007.

GUTIÉRREZ-RIVAS, C. Variación y cambio pragmático en el español de los cubanos en Miami: el efecto de la generación en el discurso bilingüe. In: GARCÍA, C.; PLACENCIA, M. E. Estudios de Variación Pragmática en Español. Buenos Aires: Dunken, 2011. p. 167-83.

KEBRAT-ORECCHIONI, C. Análise da Conversação: princípios e métodos. Tradução por Carlos Piovezani Filho. São Paulo: Parábola Editorial, 2006.

KOIKE, D. Negation in Spanish and English suggestions and requests: mitigating effects?. Journal of Pragmatics, v. 21, [S1], n. 5, p. 513-26, May, 1994.

LE PAIR, R. Spanish request strategies: a cross-cultural analysis from an intercultural perspective. In: Language Sciences 18 (3-4), p. 651-70, Jul-Oct, 1996.

MÁRQUEZ-REITER, R. Linguistic politeness in Britain and Uruguay: a contrastive study of requests and apologies. Amsterdam: John Benjamins, 2000.

A contrastive study of indirectness in Spanish: evidence from Uruguayan and peninsular Spanish. In: Pragmatics. vol 12 (1) International Pragmatics Association, p. 135-52, Jan., 2002.

MUFWENE, S. Ecologia da língua: algumas perspectivas evolutivas. In: Ecolinguística: Revista brasileira de ecologia e linguagem. Brasília v. 2, n. 1, p. 21-38. 17/02/2016.

PENNER, H.; ACOSTA, S.; SEGOVIA, M.. El descubrimiento del castellano paraguayo a través del guaraní: una historia de los enfoques lingüísticos. Asunción: CEADUC, 2012.

PLACENCIA, M. E.; BRAVO, D. Panorámica sobre el estudio de los actos de habla y la cortesía lingüística. In: Actos de habla y cortesía en español. Muenchen: Lincom Europa, 2002.

PLACENCIA, M. E. Pragmatics across varieties of Spanish. Donaire 2, p. 65-77, 1994.

SEARLE, J. R. Speech Acts. Cambridge: Cambridge University Press, 1969.

Nota do editor:

Artigo submetido para avaliação em: 30 de setembro de 2020 .

Aprovado em sistema duplo cego em: 22 de janeiro de 2021. 